\title{
The effect of embedded gypsum streaks on the dissolution of dam foundation: a case study in Iran
}

\author{
H FARSHBAF AGHAJANID \\ Department of Civil Engineering, Faculty of Engineering, Azarbaijan Shahid Madani University, Kilometer 35 \\ of Tabriz/Azarshahr Road, P.O. Box 53714-161, Tabriz, Iran \\ e-mail: h.farshbaf@azaruniv.ac.ir
}

MS received 6 May 2016; revised 5 January 2018; accepted 18 January 2018; published online 30 April 2018

\begin{abstract}
Evaporative rocks are known to have a high susceptibility to dissolution in fresh water. Substantial evidence all over the world has shown that the dissolution of evaporative rocks in the foundations of dams and basins can lead to unfortunate disasters. In a basin located in Iran, owing to dissolution of evaporative rock in the foundation on the south side, some hazardous events, such as unexpected subsidence, ground collapse, and water escape from the reservoir, have been reported. Comprehensive geological and geophysical surveys along with detailed geotechnical investigations were performed in order to assess the reasons. By analyzing the site investigation results, it is recognized that even though the foundation of the basin is composed of impervious marl layer, the dissolution of thin streaks of gypsum embedded inside the marl layer provides interconnected paths for the flow of water into the lower depths of the foundation in order to reach to halite layer located inside the marl. The geophysical survey results indicate that the zone with defects is limited to the specific area of the basin where the halite layer is located relatively near the ground surface. However, if the reservoir is filled completely again, the dissolution front may advance to other zones of the basin, and more area of the basin ground may be affected by subsidence and other relevant phenomena.
\end{abstract}

Keywords. Dissolution; halite rocks; embedded gypsum bed; subsidence; seismic refraction survey.

\section{Introduction}

Evaporative rock formations, such as halite and gypsum, are known for their high susceptibility to dissolution by water. In cases where these geological strata are located beneath a dam reservoir and the water-resistive barrier system of the dam does not function properly, the seeped water from the reservoir aggravates the dissolution process of the foundation materials. In this situation, the reservoir of the dam enhances the dissolution process of the foundation materials [1-3].

The dissolution of evaporative rocks in dam foundations can result in large cavities and porous spaces in the foundations/abutments. The presence of voids in the foundation material can provide a direct channel for the escape of water and even lead to unfavorable events, such as large subsidence and sinkholes, which may damage the dam [1, 3-10].

In order to determine the critical consequences of dissolution phenomena in reservoir and dam foundations, many researchers have focused on the dissolution mechanism in evaporative rock masses. Johnson [7] recognized that the dissolution process of halite and gypsum layers involves a combination of four main factors, namely; (1) source of fresh water, (2) presence of evaporative rock in the ground, (3) an exit pathway or drainage channel for dissolved particles to escape the ground, and (4) sufficient hydraulic energy for infiltration of fresh water into the ground. The dissolution process of halite rocks beneath reservoir foundation is illustrated in figure 1 . The fresh water seeps into the halite rock mass, and after dissolution of the salty rocks, the brine water exits the ground surface through springs, or enters underground aquifers [11]. The dissolution of halite rocks occurs at a faster rate and larger volume when compared to other types of evaporative rocks [12].

In the past decades, some evidences from around the world have suggested that the construction of dams on soluble bedrock lead to irreparable deficiencies in dam operation.

One of the most critical instances is the complete failure of Quail Creek Dike in United States [4]. Furthermore, local solution in the bedrock foundation of the Upper Mangum dam in the United States has led to the creation of many sinkholes in dam abutments and has established many pathways for the escape of reservoir water [13]. Other global case studies have also reported the dissolution of evaporative rock in dam reservoirs [5, 8, 14-17]. 

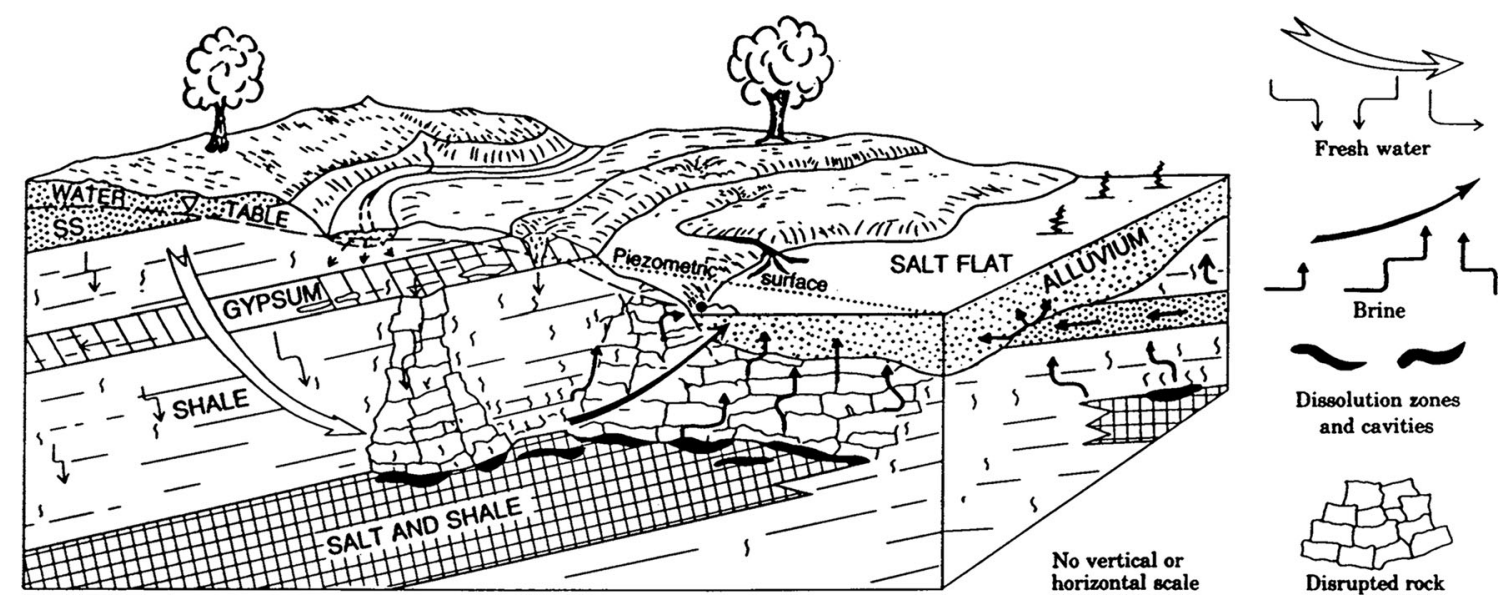

Figure 1. The schematic illustration of solution process in halite rock (after Johnson [11]).

In this paper, the dissolution process and consequent subsidence events in the foundation of the Arbatan basin in Iran are thoroughly investigated. To identify the reasons for extension of the soluble zones in the basin, a comprehensive site investigation, including subsurface drilling and geophysical surveys, was conducted, and the results are presented here. The main reasons for the dissolution are identified by analyzing the site investigation results.

\section{The Arbatan basin}

The Arbatan reservoir is located in the northwest of Iran (latitude of $38^{\circ} 10^{\prime} 50^{\prime \prime} \mathrm{N}$ and longitude of $46^{\circ} 53^{\prime} 1^{\prime \prime} \mathrm{E}$ ) at a distance of $47 \mathrm{~km}$ from Tabriz city. The reservoir site is located in a region with a cup shaped topography, which is appropriate for storing water. Thus, embankments with small heights are constructed around the basin, and water is diverted from the main river to the basin through an open channel. The total volume of the Arbatan reservoir is about $20 \mathrm{MCM}$. The main purpose of this dam is to supply water for irrigating 3500 hectares of agriculture land in this region.

For completing the reservoir, six earthfill dykes named A to $\mathrm{F}$ have been constructed at the circumference of the basin, as shown in figure 2. Dyke A (length $=1260 \mathrm{~m}$; height $=7 \mathrm{~m}$ ) is located on the eastern side of the basin. Dykes B to E are constructed on the southern side of the basin. The average height of all south-side dykes is about $7 \mathrm{~m}$ above the basin ground level. The lengths of dykes B, $\mathrm{C}, \mathrm{D}$, and $\mathrm{E}$ are $418,202,280$, and $514 \mathrm{~m}$, respectively. At the northwest corner of the basin, dyke F (length $=190$ $\mathrm{m}$; height $=5 \mathrm{~m}$ ) is constructed to close and limit the reservoir.

All dykes are constructed as earthfill dams composed of central clay core, a vertical filter in the downstream direction, and outer shells in the upstream and downstream directions filled with coarse-grained materials. With respect to the flat ground of the basin, the height of the reservoir level from the bottom of the basin is uniformly identical in most of the basin zones, and the maximum height of the reservoir is about $10 \mathrm{~m}$. The construction of the Arbatan basin dykes was completed in 2002, and the reservoir has been in operation since 2003 .

\section{Review of previous events}

Four years after the first impounding of the Arbatan basin, which functioned as land irrigation supply, some critical events occurred on the south margin of the basin, which have raised concerns of threat to the dam safety. Owing to the high likelihood of hazardous accidents, the operation of the reservoir was terminated, and the reservoir level was lowered to near empty. The main concern was a large ground subsidence event at the south side of basin, beginning from the basin ground and extending downstream. The initiation location of the subsidence area (denoted by subsidence band) is found inside the reservoir and in front of the dyke $\mathrm{D}$ axis at a distance of $450 \mathrm{~m}$. The subsidence band then intersects the dyke $\mathrm{D}$ axis and continues downstream along a curved path with length of $1160 \mathrm{~m}$ and width of $60 \mathrm{~m}$. Figure 3 shows the layout of the subsidence band inside the basin, and its extension in the downstream direction along the ground.

The subsidence has altered the ground surface formation and its topography. Even though the land before the subsidence was almost flat, a long valley with a limited width, and a maximum trough of $3 \mathrm{~m}$, has been created along the subsidence band (figure 4). The ground outside the subsidence band has remained unchanged, the former flat topography being retained. At the boundary of the subsidence band with the flat ground, several parallel longitude crack lines have emerged at the stepped levels, as shown in 


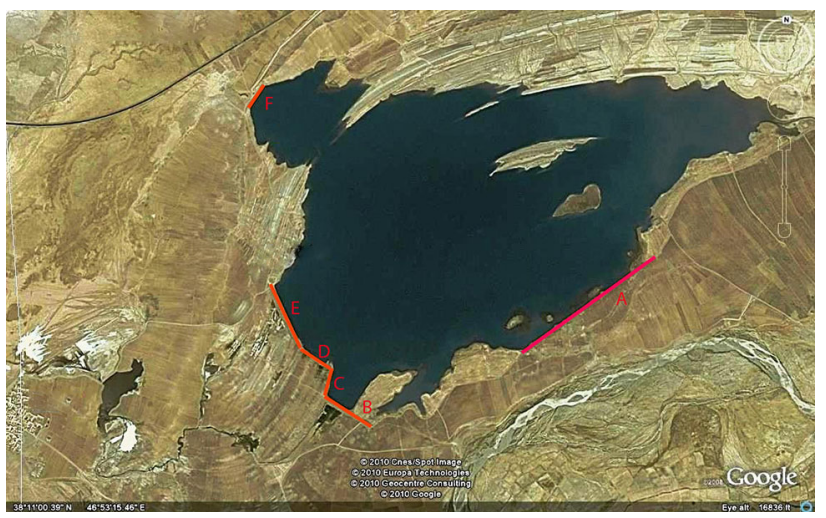

Figure 2. The plan view of Arbatan reservoir in full condition and circumference dykes.

figure 5. The opening of these breakdown lines varies from 1 to $40 \mathrm{~cm}$.

Furthermore, the subsidence has affected the embankment body of dyke D and caused a settlement of around $1 \mathrm{~m}$ in the dyke crest. Figure 6 shows the deformed form of dyke $\mathrm{D}$ axis. The crest settlement gradually increases along the dyke axis, and the maximum settlement of the dyke is seen at the center of the dam axis, which is coincident with the center line of the subsidence band. Outside the subsidence band, the dykes are unaffected and have retained their original form.

Apart from the subsidence, some sinkholes had formed within the reservoir, as shown in figure 3. Two sinkholes were located just $2 \mathrm{~m}$ in front of the initiating point of the subsidence band within the basin, and the average depth and diameter of these sinkholes are $1.5 \mathrm{~m}$ (figure 7). The third sinkhole is adjacent to dyke D. According to inspection reports and accounts from witnesses, when the reservoir was full, water escaped through the upstream sinkholes and created whirlpools.

Along with the emergence of the subsidence band, there is some evidence of water escape from the reservoir. The water entered into the sinkholes and exited through the springs downstream of dyke $\mathrm{D}$, and the location of the exit springs is shown in figure 3 . The entry and exit point of the water is completely coincident to the start and end points of the subsidence band. This indicates that these two events correspond to each other.

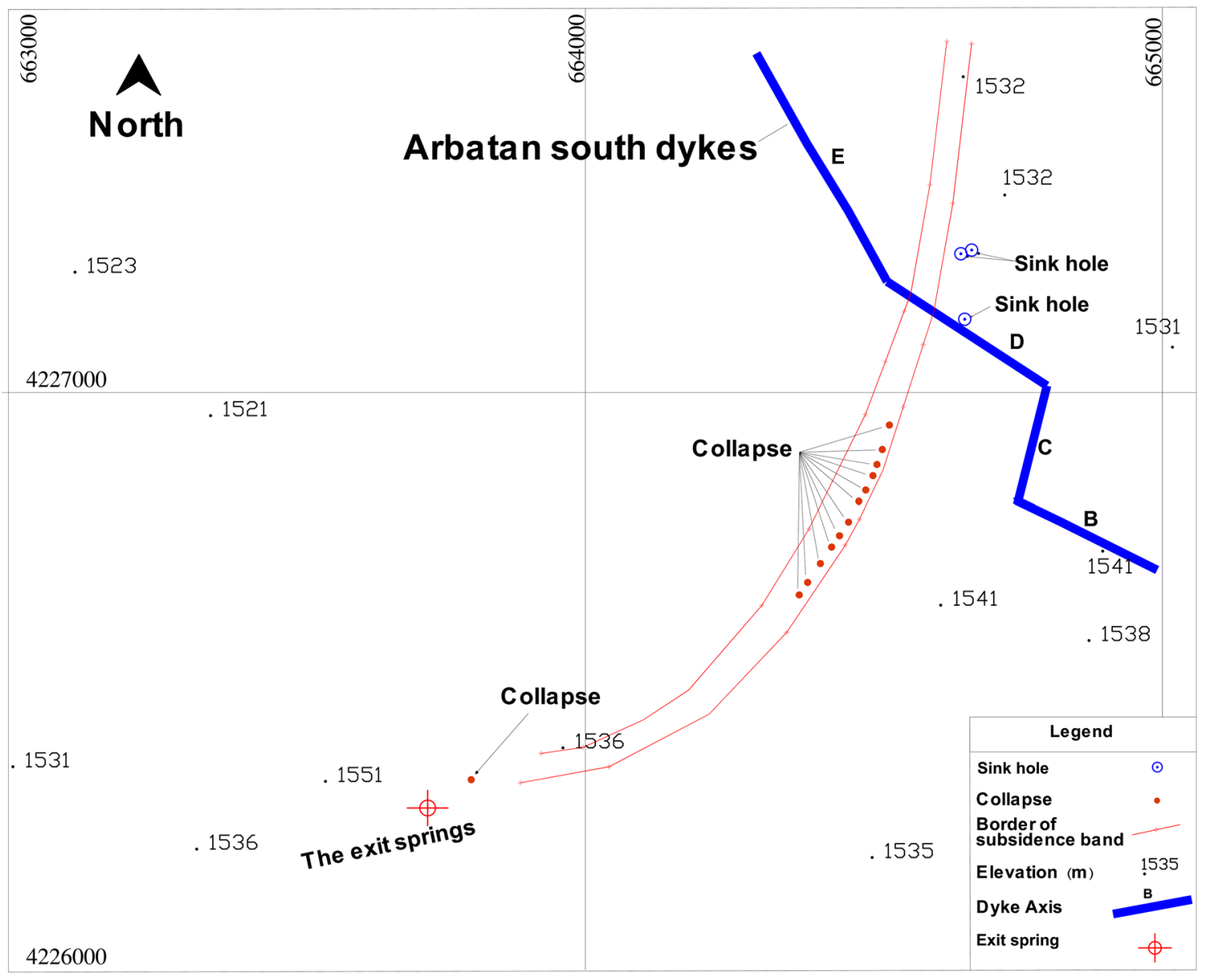

Figure 3. The layout of subsidence band, collapsing sinkholes in downstream, exit spring (the coordinates are expressed in UTM system). 


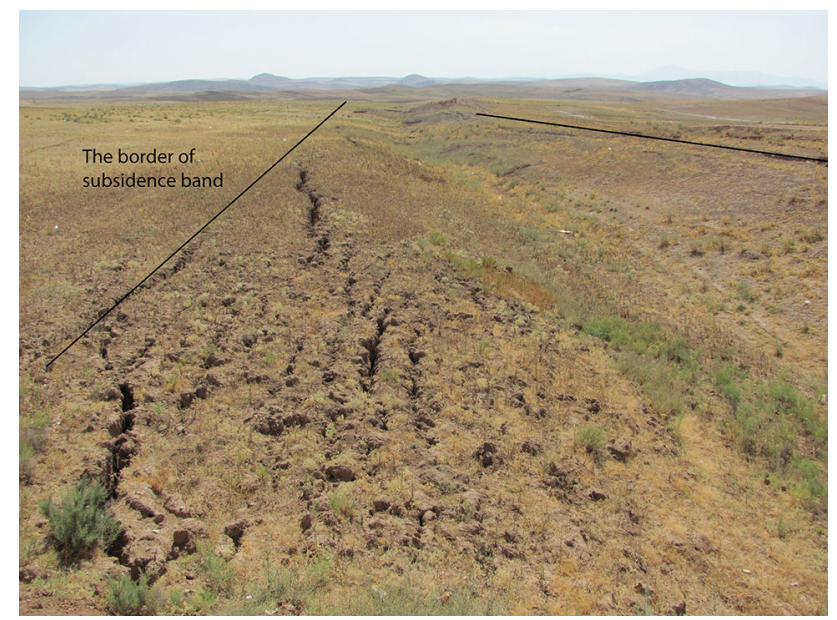

Figure 4. A view of the subsidence band from dyke D toward the downstream of basin.

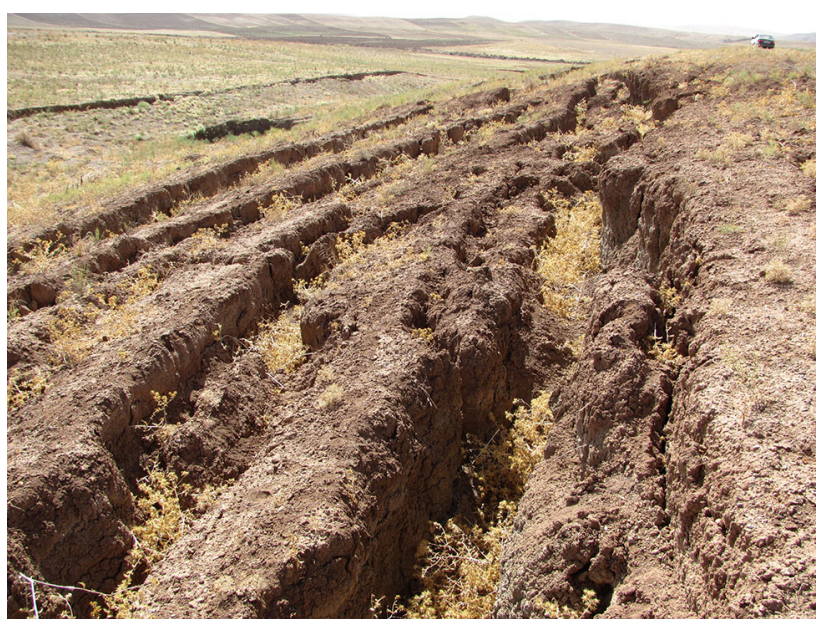

Figure 5. The elevated break lines with considerable opening at the border of subsidence band.

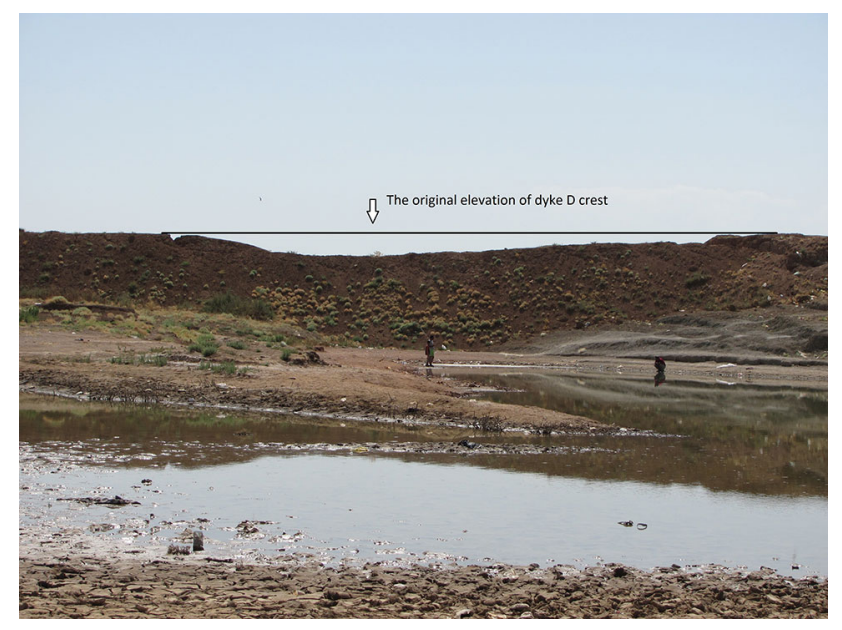

Figure 6. The extra settlement of dyke D crest (view from basin toward the dam).
Besides the aforementioned phenomena, a total of 13 sinkholes and collapsed zones are located downstream of dyke D. Twelve of these collapsing holes are regularly scattered along a curved path of length $500 \mathrm{~m}$ following the boundary of the subsidence band. The latest sinkhole is located near the end of the subsidence band near the exit spring of escaped water. It should be noted that these collapsing sinkholes have occurred simultaneously with the development of the subsidence, and the diameter and depth of the sinkholes gradually increase with the subsidence depth. Most of the sinkholes have a funnel-shaped opening (figure 8), and the diameter of the collapsing sinkholes are in the range of 3 to $12 \mathrm{~m}$. Figure 9 shows the largest sinkhole with a diameter of $13 \mathrm{~m}$.

\section{Geology of reservoir foundation}

For investigation of the geological background of the aforementioned events in the Arbatan basin, a comprehensive site investigation program, including surface inspection, subsurface investigation, and geophysical survey, was conducted after the reservoir was discharged. During this program, eleven boreholes named BH1 to BH10 were drilled inside the affected zone of the reservoir and next to the south axis of the basin. Further, for studying the geological condition of the intact zone of reservoir foundation, three boreholes named BH11 to BH13 were drilled inside the reservoir and outside the subsidence band. The depth of the boreholes is between 50 and $60 \mathrm{~m}$. The locations of boreholes are shown in figure 10 .

The geological profile of the basin along boreholes BH1 to BH10 (indicated by the AA line in figure 10) is shown in figure 11(a). Accordingly, the geological formations of the basin foundation from the surface to the lower depths comprise of the following layers: 1) shallow fine grained sediment of reservoir with thickness up to $3 \mathrm{~m}, 2$ ) upper marl layer with embedded gypsum, 3) evaporative rock of halite with varying thicknesses, and 4) lower marl layer.

The upper marl layer extends throughout the basin foundation, whereas the gypsum is embedded within the upper marl layer in two different modes: embedded flocculate beds and narrow thin streaks. In some locations, the gypsum amount in the upper marl layer is higher, and the gypsum outcrops as an independent interlayer within the marl unit. Thus, it is preferable to identify the upper layer as gypsum-marl. Figure 12 gives a close view of the embedded gypsum beds and streaks inside the upper marl layer.

The halite rocks are found in the south side of the basin at an average depth of $35 \mathrm{~m}$ below the ground surface with various thickness. The thickest portion of this geological formation is located beneath dyke D with a thickness of 15 $\mathrm{m}$, but in the left and right hand side of the south axis of the basin, the thickness of halite layer is lower, around $1 \mathrm{~m}$. 


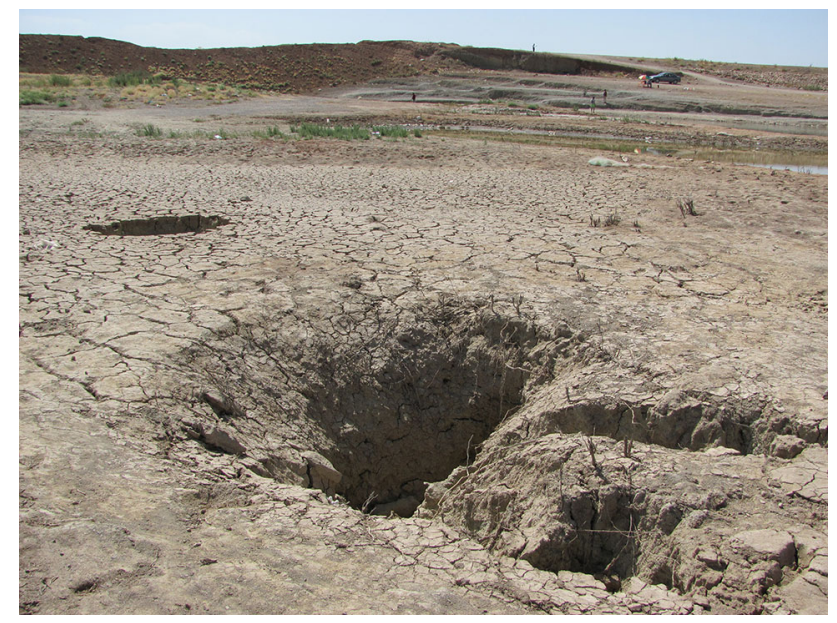

Figure 7. The sinkholes within basin and just in front of subsidence band.

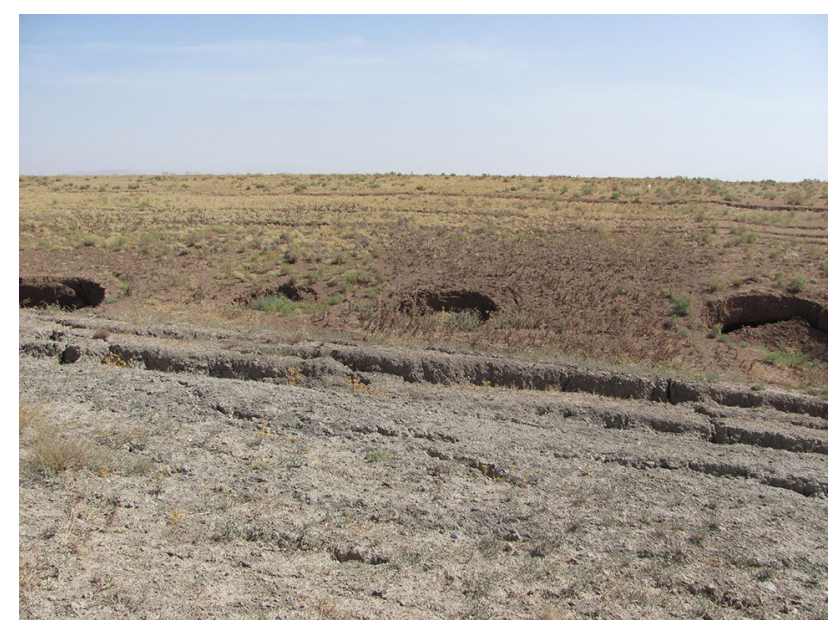

Figure 8. The collapsing sinkholes in downstream of dyke D situated along the border of subsidence band.

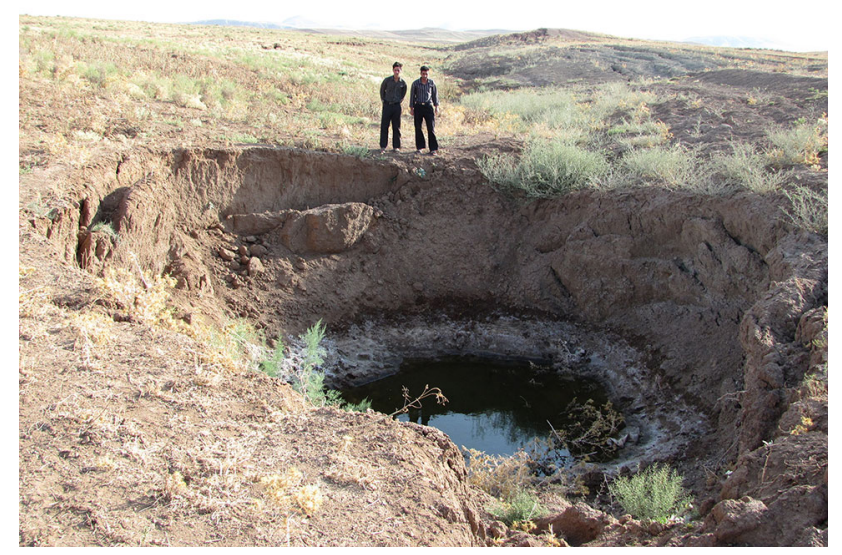

Figure 9. The opening of largest collapsed sinkholes in downstream of dyke D.
Beneath the subsidence zone and just at the center of the dyke $\mathrm{D}$ axis, a smooth falling and break down is found in the halite layer. Furthermore, even though the halite layer samples obtained from boreholes outside the subsidence band which exist in pure form, the halite unit in borehole $\mathrm{BH} 1$ located in the subsidence band is present in distributed form as a mixture with the marl. In fact, the subsidence of the ground surface is related to halite layer disturbances and break down. Similar to the upper marl, the lower marl layer mainly consists of marl formation and contains some embedded gypsum beds.

The geological profile of the intact zone of the basin along section line BB (connecting boreholes BH10, BH11, and $\mathrm{BH} 12$ ) is shown in figure 11(b). The general layout of geological formations in the middle area of the basin is similar to that detected at the south side, and from the ground surface to lower depths, the reservoir foundation is comprised of last Quaternary sediments and upper marl layer with embedded gypsum. In this region, the thin evaporative halite layer is located at a depth of more than $50 \mathrm{~m}$. From east to west of the basin, the depth of this geological formation gradually increases, and in borehole BH10, the halite layer is not detected even up to a depth of $60 \mathrm{~m}$. However, in contrast to the south side of basin, no disturbance due to subsidence or other phenomena was found in samples obtained from this layer, and the halite layer exists in intact and pure form.

For evaluating the hydraulic conductivity of the basin foundation, the water pressure test (Lugeon test) [18] was conducted in all boreholes. The graph of Lugeon values versus depth in all boreholes located along the south axis of the basin is presented in figures 13(a) and 13 (b). As seen, the permeability in the upper marl layer inside the subsidence zone (figure 13(a)) varies considerably. The highest permeability in the upper marl formation is associated with the zone near dyke $\mathrm{D}$ where the subsidence occurred. When going further from the subsidence band toward the side of the south axis, the permeability of the upper marl is reduced, such that in the east and west hands of the south side of basin, the upper marl behaves as an impervious material. The high permeability zones of halite layer are located beneath the subsidence band and in front of dyke D. In contrast to the upper marl layer, the lower marl layer has a permeability lower than 1 Lugeon in all boreholes at the south side of the basin, and thus, the lower marl can be identified as impervious.

The graph of Lugeon values versus depth in all three boreholes located along the $\mathrm{BB}$ line is presented in figure 13(c). The permeability of all layers, except the upper marl at depths between 7 and $10 \mathrm{~m}$ of borehole BH-10, is less than 1 Lugeon. This fact indicates the more intact and impervious condition of the upper marl layer located outside the subsidence band. Moreover, the evaporative halite rock in the intact zone behaves as an impervious unit, and no evidence of water escape is observed in this layer. 


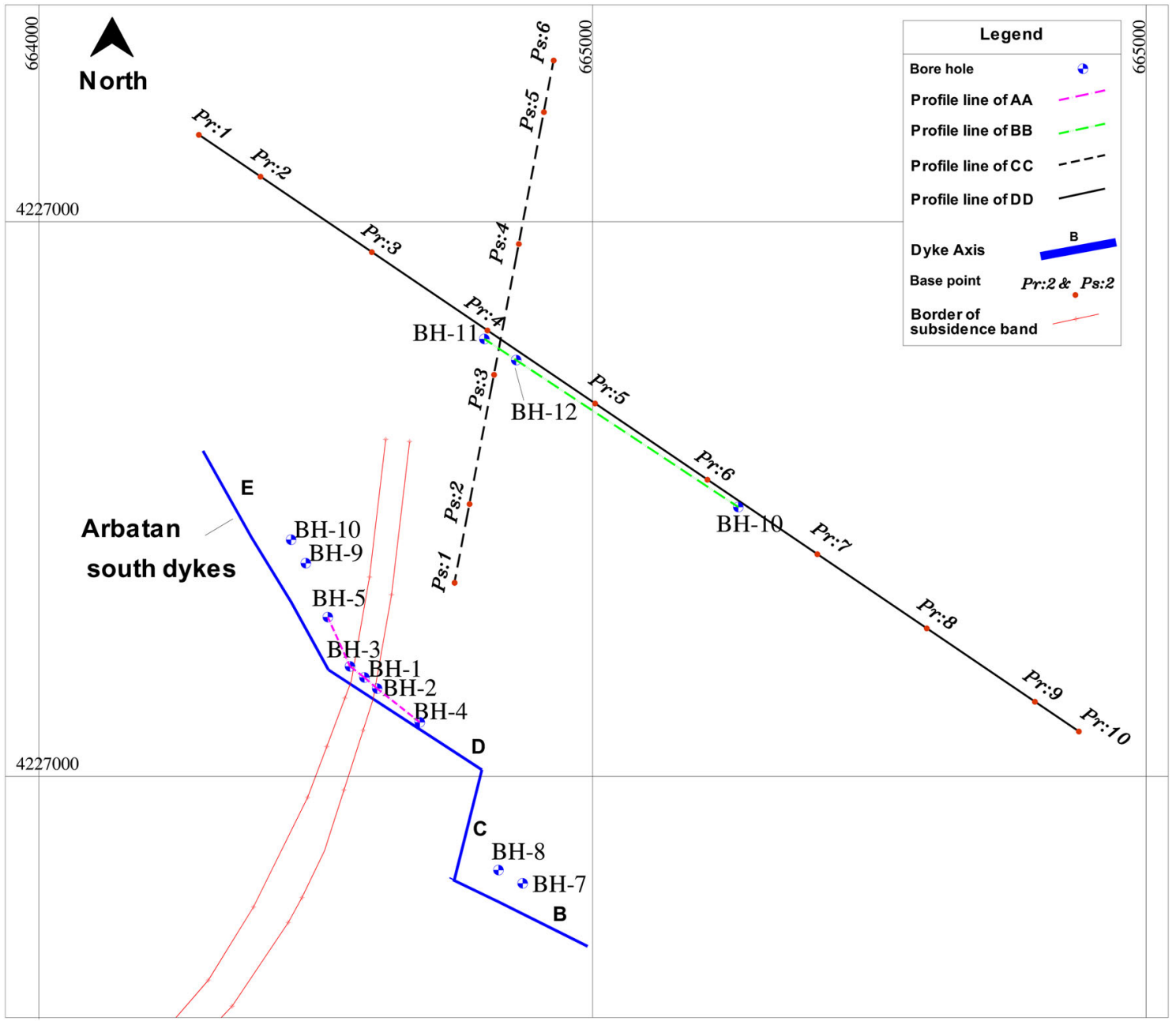

Figure 10. The location of boreholes and seismic refraction profile lines in Arbatan basin (the coordinates are expressed in UTM system).

Top sedimetation soil

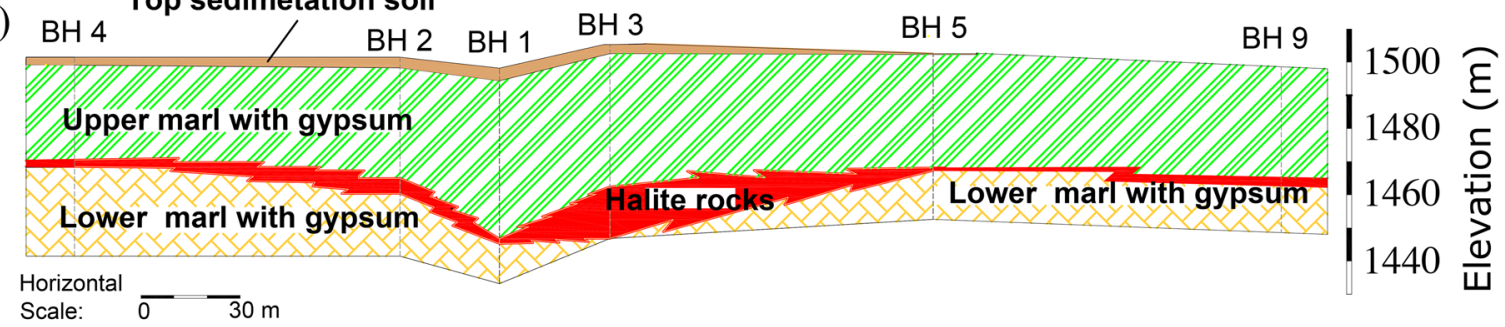

(b)

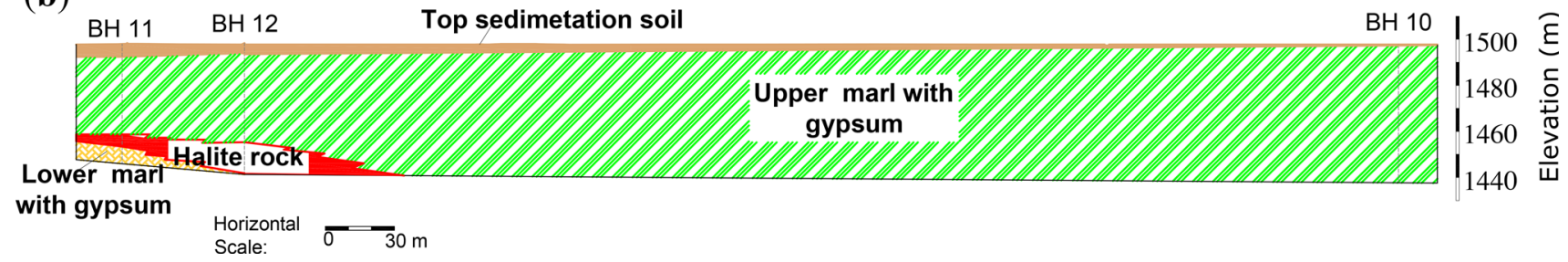

Figure 11. The geological (longitude) profile of basin foundation: (a) along the AA line (situated next to the south side of basin and within the infected subsidence band), (b) along the BB line (situated out of subsidence band). 

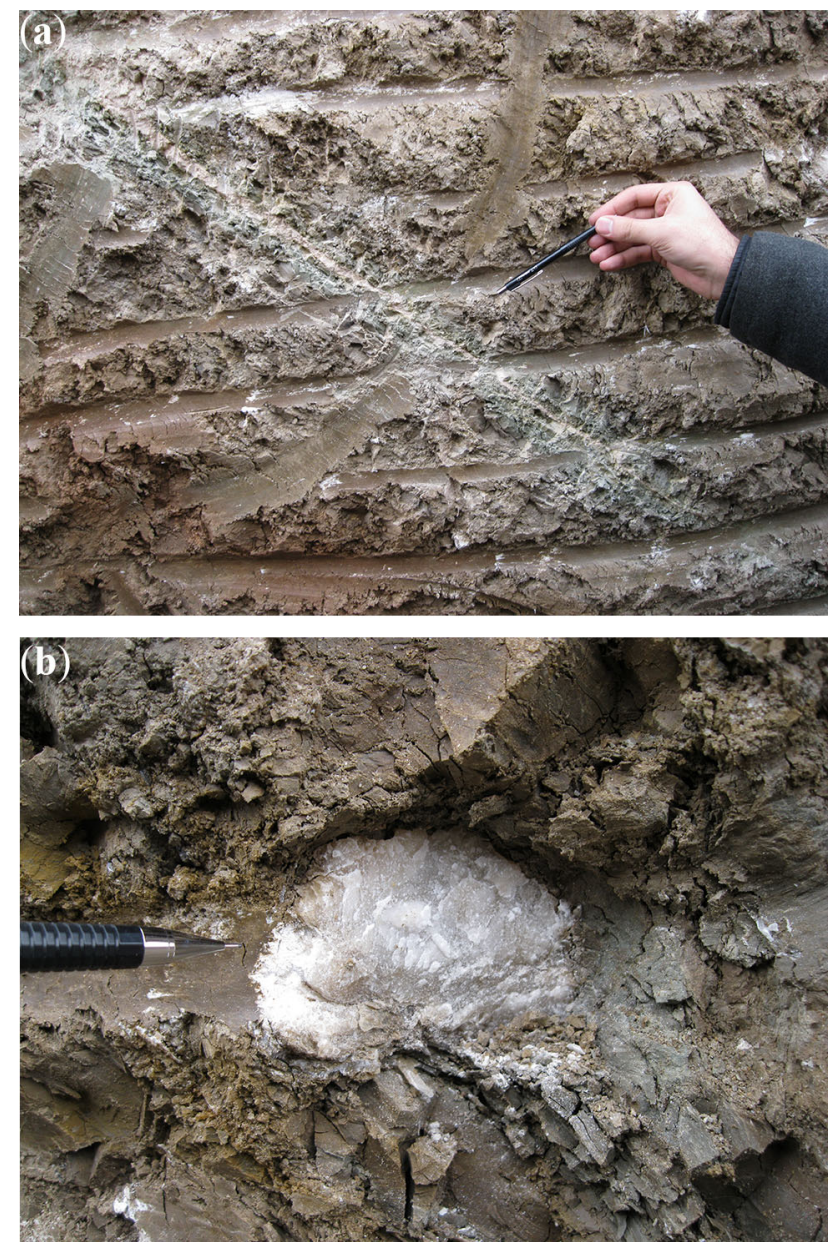

Figure 12. A close view of gypsum embedded inside the upper marl layer: (a) in the form of gypsum beds, (b) in the form of thin streaks.

Tables 1 and 2 present the chemical components of all geological units in both the subsidence band and the intact zone of the basin. The upper marl layer contains a considerable amount of gypsum and sulfate components such that the gypsum fraction of the upper marl layer is found more in the intact zone than in the subsidence zone. In contrast, the total dissolved salt (TDS) and gypsum fractions of the halite layer located within the subsidence zone is higher than the chemical components of this layer beneath the intact zone.

\section{Seismic refraction survey of basin ground}

To identify the extent and properties of the subsidence band inside the Arbatan basin, a comprehensive seismic refraction geophysical survey was carried out in the basin region, in accordance with the ASTM D5777 procedure [19]. During this programme, the response of the basin ground against seismic excitation was recorded along 38 profiles. In 30 profiles, geophones were installed along the straight lines at a distance of $10 \mathrm{~m}$, and excitation is induced by an explosive source. In other profiles, geophones are located at a distance of $50 \mathrm{~m}$ in order to capture thin layers by increasing the survey's resolution, and the induced energy is supplied via a sledge hammer. By analyzing the plot of travel times against the distance between the source and the geophones, the depth and seismic p-wave velocity of each layer were identified.

The profile of P-wave velocity along the profile line of CC is shown in figure 14(a). In figure 10, the layout of the $\mathrm{CC}$ profile line is shown to be perpendicular to the dyke $\mathrm{D}$ axis and to extends toward the basin center. Based on the detection of the refracted waves, the shallow stratum of the basin ground denoted as R1 zone has a low P-wave velocity in the range between $940 \mathrm{~m} / \mathrm{s}$ at point No.17 and $1120 \mathrm{~m} / \mathrm{s}$ at the end of the profile line. According to the subsurface drilling data, this zone comprised recent fine-grained sediments, and a low transmitting velocity is common for this type of material [20]. The thickness of this zone increased from the south side toward the basin center.

Beneath the shallow sedimentary strata, the P-wave velocity of the ground is higher. However, two distinguished zones with different range of $\mathrm{P}$-wave velocities are detected, referred to as R2 and R3 zones in figure 14(a). The R2 zone is located close to the south side of the basin and has a relatively low P-wave velocity in comparison to the other zone. The horizontal extension of the R2 zone toward the basin center is limited to a region between points No. 18 and No. 19, and this zone almost covers the bottom of the subsidence band in the basin. The lowest $\mathrm{P}$-wave velocity in this zone is recorded at the nearest point to the dyke $\mathrm{D}$ axis with a value of $1580 \mathrm{~m} / \mathrm{s}$, and as moving toward the basin center, the wave velocity in this zone increases up to $2320 \mathrm{~m} / \mathrm{s}$. By comparing the R2 zone with the geological subsurface profile, it is recognized that the R2 zone covers both upper marl and evaporative halite rock layers, where these geological formations are attributed to high permeability.

In depths lower than that of the R2 zone, the P-wave velocity of the ground is considerably increased up to 3080 $\mathrm{m} / \mathrm{s}$. Similarly, as we move away from the R2 zone toward the R3 zone at the same depth, the velocity of waves is increased to more than $3000 \mathrm{~m} / \mathrm{s}$. Furthermore, the boundary between the R2 and R3 zones in the upper marl layer is coincident to the border of the subsidence band located between points 3 and 4 (Ps. 3 and Ps. 4) in figure 14(a).

It should be noted that the geological subsurface condition of the basin is almost similar in both the R2 and R3 zones, and the ground is composed of the marl layer with embedded gypsum. The different range of P-wave velocities in the upper marl layer along the direction perpendicular to the south axis of the basin is attributed to the variation in the porosity in the identical material type. In other words, the upper marl layer at the basin center has lower porosity and hence higher wave velocity. 

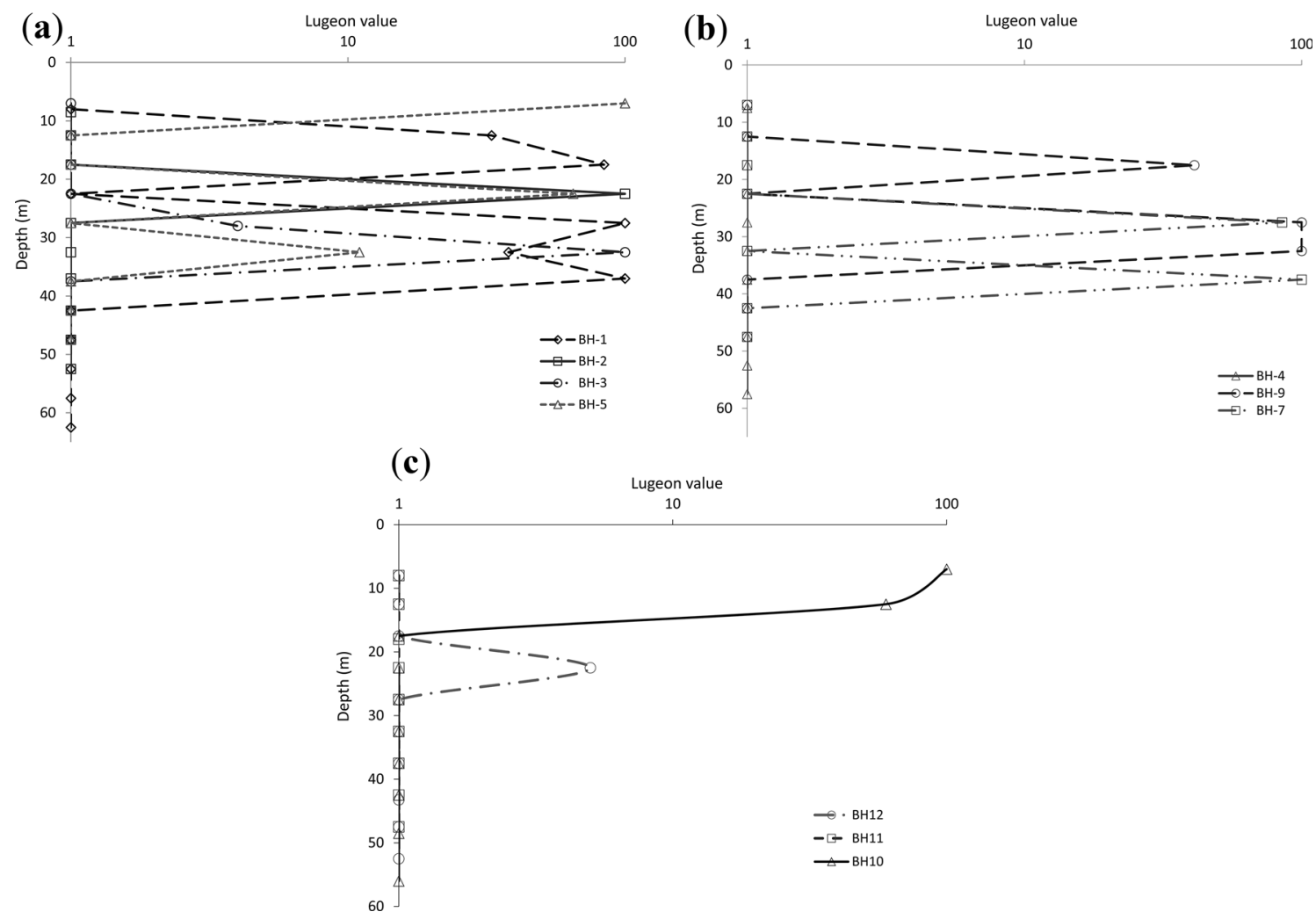

Figure 13. The graph of permeability versus depth in: (a) boreholes located near the south side of basin and inside of subsidence band of reservoir (along the profile line of AA); (b) boreholes outside of subsidence band; (c) boreholes located along the profile line of BB (out of subsidence band of reservoir).

Table 1. The chemical specification of ground layers inside the subsidence band.

\begin{tabular}{lcccrrr}
\hline Layer name & Organic Matter & $\mathrm{Cl}^{-}(\mathrm{ppm})$ & $\mathrm{SO}_{4}{ }^{2-}(\mathrm{ppm})$ & Gypsum content $(\%)$ & $\mathrm{TDS}(\mathrm{ppm})$ & $\mathrm{pH}$ \\
\hline Upper marl & 0.8 & 6216.6 & 413.73 & $12.59 \%$ & 7.26 \\
Halite rock & & 28360 & 512 & $21.60 \%$ & 6.60 \\
Lower marl & 0.33 & 24815 & 416 & $23.00 \%$ & 61200 & 37500 \\
\hline
\end{tabular}

Table 2. The chemical specification of ground layers outside the subsidence band.

\begin{tabular}{lccccr}
\hline Layer name & Organic Matter & $\mathrm{Cl}^{-}(\mathrm{ppm})$ & $\mathrm{SO}_{4}{ }^{2-}(\mathrm{ppm})$ & Gypsum content $(\%)$ & $\mathrm{TDS}(\mathrm{ppm})$ \\
\hline Upper marl & 0.79 & 6469.78 & 176.33 & 0.17 & $\mathrm{pH}$ \\
Halite rock & 0.78 & 3545 & 544 & 0.078 & 7.21 \\
\hline
\end{tabular}

The P-wave velocity profile of the basin ground along east-west direction (coincident to profile line of DD in figure 10) is shown in gigure 14(b).. Similar to the seismic refraction profile of CC line, the shallow sedimentary soil layer of basin ground (denoted by $\mathrm{T} 1$ zone) has the lowest $\mathrm{P}$-wave velocity in the range between 520 and $1020 \mathrm{~m} / \mathrm{s}$. At lower depths, where the main strata are mainly comprised of marl rock, the P-wave velocity of ground is significantly increased. However, in the region with limited extension, referred to as zone T2, the P-wave velocity is considerably lower than in other regions with identical depth, and the maximum value P-wave velocity in this zone is $2030 \mathrm{~m} / \mathrm{s}$. Zone T2 is exactly positioned beneath the subsidence band of the basin, and this zone completely covers the width of the subsidence band. Further, the maximum thickness of the T2 zone is situated at the center line of the subsidence band, 

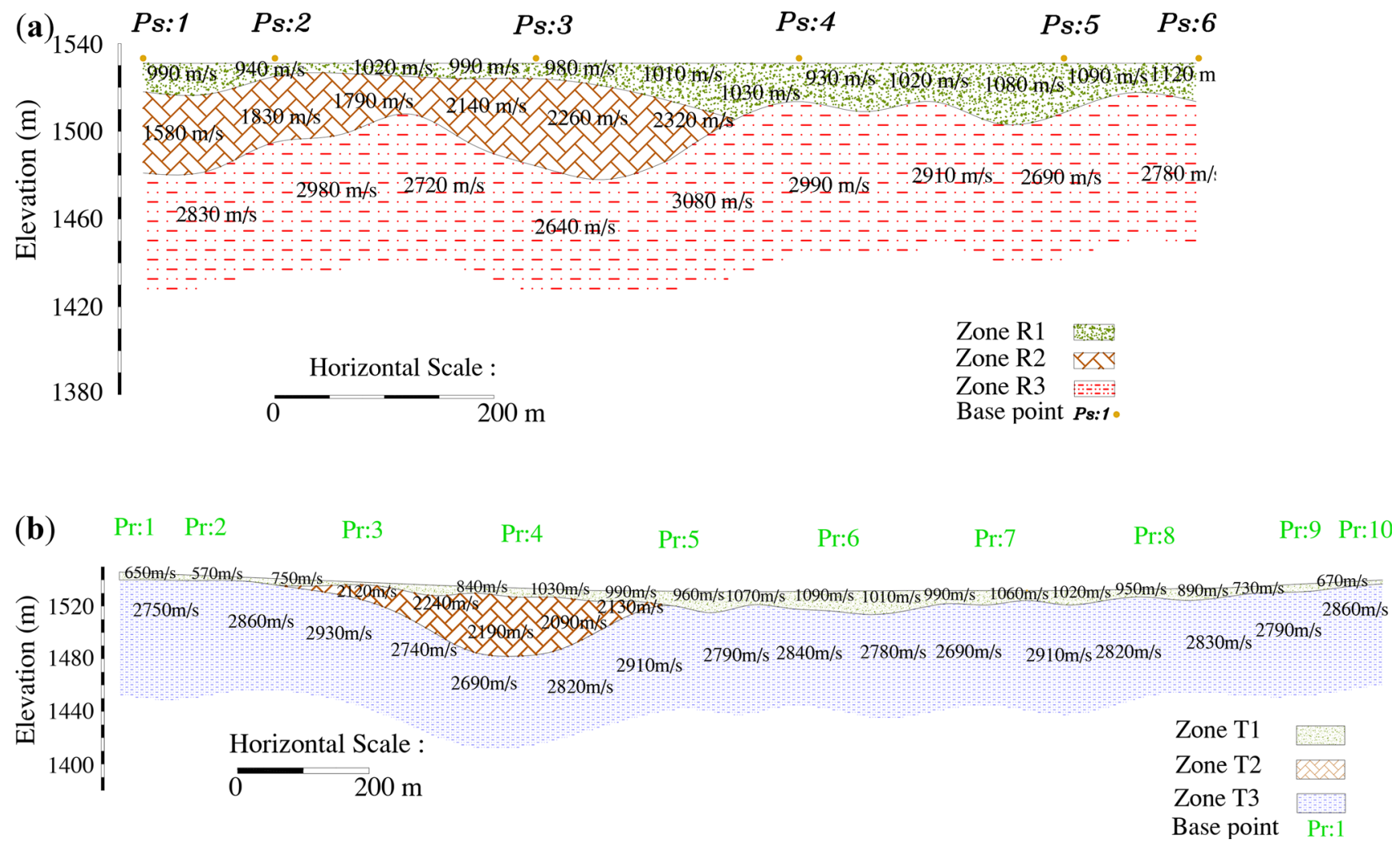

Figure 14. The profile of P-wave velocity (thought in $\mathrm{m} / \mathrm{s}$ ): (a) along the profile line of CC (in north-south direction), (b) along the profile line of DD (in east-west direction).

and by moving away toward the edge of the subsidence band, the thickness of this zone decreases. Outside the T2 zone, i.e., in the T3 zone, the P-wave velocity of ground is considerably increased and reaches a value of more than $2800 \mathrm{~m} / \mathrm{s}$, which is the typical magnitude of P-wave velocity in marl rocks [20].

\section{Discussion on the geotechnical background of Arbatan basin subsidence}

The major subsidence event that occurred in the Arbatan basin is closely associated with existing zones within the basin foundation that are recognized to have high porosity and permeability. The foundation of the Arbatan basin is mainly composed of a marl layer, with embedded thin streaks of gypsum. The high susceptibility of gypsum dissolution and the availability of water in the reservoir with adequate energy led to flow of water into the foundation and to the gradual dissolution of gypsum inside the marl layers. Therefore, further voids emerged inside the marl layer at some zones, thus decreasing the density and increasing the permeability.

To clearly detect the dissolution of gypsum beds, the variation of gypsum content at different depths of boreholes at the south-side of the basin is illustrated in figure 15(a). Furthermore, the in situ dry density of marl samples obtained from these boreholes is presented in figure 15(b). In boreholes located inside the subsidence zone of the basin (e.g., boreholes $\mathrm{BH}-02, \mathrm{BH}-01$, and $\mathrm{BH}-05$ ) and up to a depth of $20 \mathrm{~m}$, the gypsum content in the marl layer is less than $10 \%$. At lower depths, the gypsum content of the marl layer is significantly higher and increases up to more than $20 \%$. However, the in-situ density of the upper marl layer up to a depth of $20 \mathrm{~m}$ is lower, and with increasing depth, the density of the layer also increases. This fact implies that even though the gypsum content in the lower marl layer is found to be higher than that in the upper marl layer, the gypsum component in the lower marl layer remained intact, whereas the gypsum beds in the upper marl are diminished, thus increasing the porosity of the upper layer. The high permeability and low $\mathrm{P}$-wave velocity in the upper marl in comparison with the lower marl confirms the mentioned finding about the high degree of porosity in the upper marl layer due to solution.

Regarding the scattered distribution of soluble gypsum beds and streaks inside the upper marl layer, the dissolution process supplies further paths for the flow of water from the reservoir toward the lower parts of the ground. When an appropriate exit channel is available at lower depths, the dissolution process of the embedded gypsum is enhanced. At the south side of the basin, the evaporative halite rock layer is located at an average depth of $35 \mathrm{~m}$, and as we move toward the center of basin, the location depth of this 
(a)

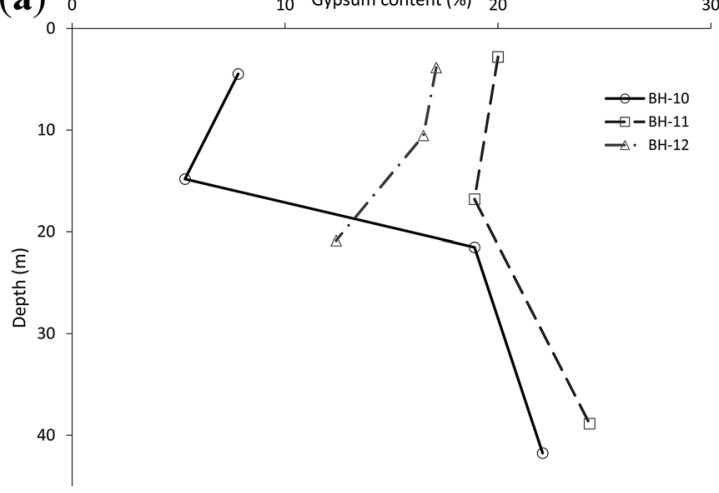

(b)

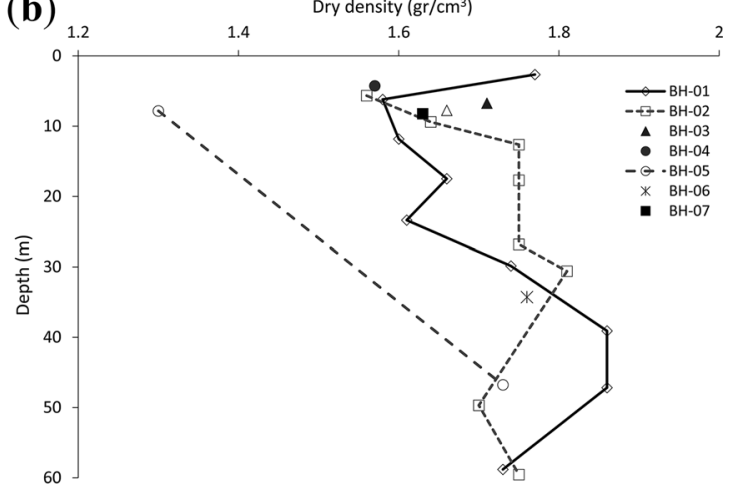

Figure 15. The graphs of material specification in boreholes located inside the subsidence band (next to south side of basin): (a) gypsum content versus depth, (b) in-situ dry density versus depth

layer is increased. Thus, in an area near dyke D, the water can easily flow through induced void spaces on the marl and reach the halite rock layer. Thus, the dissolution of halite layer is accelerated [3, 7] and ground water quality tends to salinity. To complete the dissolution process, the saline water travels through the halite layer and finally reaches the ground surface through downstream exit springs, as shown in figure 3.

The gradual dissolution of the halite layer reduces the bearing resistance of soluble strata. This phenomenon leads to subsidence and related events in the basin, and downstream valley and creates a disturbance in the halite and upper marl layer, which is obviously detected in the subsurface investigations (see figure 11(a)).

The graph of gypsum content and dry density in boreholes located in front of the subsidence band of the basin (e.g., boreholes of $\mathrm{BH}-10, \mathrm{BH}-11$, and $\mathrm{BH}-12$ ) is shown in figure 16. The gypsum content in the upper marl layer is considerably higher than $15 \%$ at all depths, except for a depth of $21 \mathrm{~m}$ in borehole BH10. In contrast, the dry density of the marl layer in this region is measured to be more than $1.7 \mathrm{gr} / \mathrm{cm} 3$ at all depths of BH12 and BH10. This implies that the gypsum content in the marl layer remains intact and is not affected by the dissolution.

By comparing the gypsum content, dry density, and the P-wave transmission velocity in the intact region of the basin with those in the subsidence band, it is recognized that as we move away from the south side toward the center of the basin, the intensity and penetration depth of the dissolution front in the marl layer is reduced. Thus, the extension of the soluble zones of embedded gypsum beds in the basin ground is restricted to specified zones that are recognized as low P-wave velocity zones in the seismic refraction survey (e.g., R2 and T2 zones in figure 14(a) and 14(b) respectively) and are exactly located beneath the subsidence zone.

The less effectiveness of the dissolution front in the center of the basin is due to two reasons. First, the evaporative halite rocks, which act as the exit channel and play a complementary role in the exit of the soluble water toward the ground surface, are located at lower depths in the center of the basin in comparison to the south side. Thus, the advancement of the dissolution front in the upper marl toward lower depths requires more time. Besides, the reservoir of the Arbatan was under operation only for two
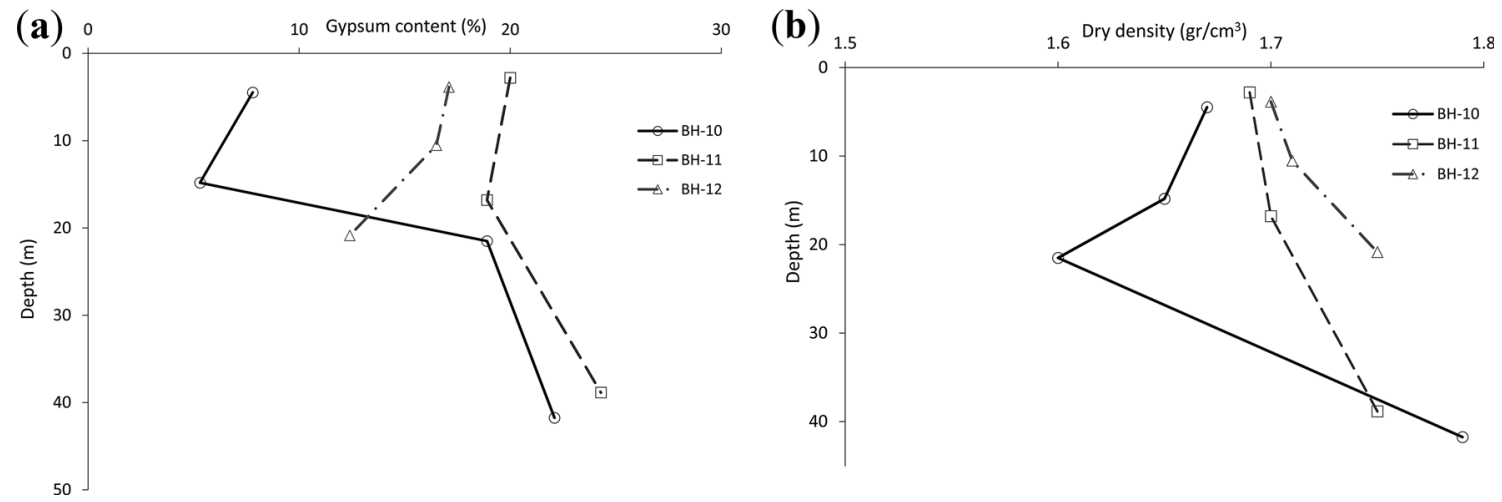

Figure 16. The graphs of material specification in boreholes located along the profile line of BB: (a) gypsum content versus depth; (b) in-situ dry density versus depth. 
years, and if the reservoir remained in full capacity for a long time, the dissolution front would have proceeded toward the center of the basin and subsidence would have occurred in most parts of the basin.

\section{Conclusions}

In this paper, the dissolution process and the relevant subsidence event in the Arbatan basin were comprehensively studied. Regarding some specific conditions, it can be said that the case study of the Arbatan basin is one of the most unique examples in the world. The first aspect of this case is the small height of the reservoir. The maximum height of the Arbatan reservoir is up to $10 \mathrm{~m}$, and hence, the initial subsurface site investigation studies were conducted up to a depth few meters greater than the reservoir height. This is reasonable for the depth of geotechnical investigations; however, since the evaporative layer of halite rocks were located in relatively deeper depths, this hazardous case was not correctly detected. Further, the existing evaporative gypsum streaks and beds inside the semi-impervious marl layer enhanced the dissolution process. By dissolution of the embedded gypsum material, interconnected voids were established, which provided adequate paths for the flow of water from the reservoir toward the halite layer.

The dissolution phenomenon and the relevant subsidence event were initiated from the south side of the basin, and the highest intensity of this event is observed in this region of the basin. This is due to the low depth of evaporative halite rocks from the ground surface and the small distance for water to travel in order to reach the halite layer. As we move toward the center of the basin, the depth of the halite layer is increased, and hence, the intensity of the dissolution process of embedded gypsum in marl and halite rocks decreased. Hence, currently, the advancement of the dissolution front toward the basin center is limited. However, if adequate water in the reservoir is supplied, the dissolution process may continue and affect more regions of the basin foundation, which may enlarge the subsidence zone in the basin.

\section{Acknowledgements}

The East Azarbaijan Agriculture Jihad Organization and Ati Negar Omran ANO consulting Engineers are gratefully acknowledged for providing the data of subsurface and geophysical investigations.

\section{References}

[1] Bedmar A P and Araguas L 2002 Detection and the prevention of leaks from dams. Netherland: CRC Press, 6-11
[2] James A and Kirkpatrick I 1980 Design of foundations of dams containing soluble rocks and soils. Q. J. Eng. Geol. Hydrogeol. 13(3): 189-198

[3] Nedriga V and Dem'yanova É 1986 Construction of dams on soils containing soluble salts. Power Technol. Eng. 20(2): 116-121

[4] Payton C and Hansen M 2003 Gypsum karst in southwestern Utah: failure and reconstruction of Quail Creek Dike. Evaporite karst and engineering/environmental problems in the United States. Okla Geol. Surv. Circ. 109: 293-303

[5] Adamo N, Al-Ansari N, Issa I E, Sissakian V and Knutsson S 2015 Mystery of Mosul dam the most dangerous dam in the world: Foundation treatment during construction. J. Earth Sci. Geotech. Eng. 5(3): 59-69

[6] Johnson K S 2008 Gypsum-karst problems in constructing dams in the USA. Environ. Geol. 53(5): 945-950.

[7] Johnson K S 1981 Dissolution of salt on the east flank of the Permian Basin in the southwestern USA. J. Hydrol. 54(1): 75-93

[8] Piqueras J M, Pérez E S and Menéndez-Pidal I 2012 Water seepage beneath dams on soluble evaporite deposits: a laboratory and field study (Caspe Dam, Spain). Bull. Eng. Geol. Environ. 71(2): 201-213

[9] Shafiei A, Dusseault M and Baghdardokht Z 2008 Geotechnical Properties of Soluble Rocks from a Dam Site in Iran. In: The 42nd US Rock Mechanics Symposium (USRMS). American Rock Mechanics Association.

[10] Waltham T, Bell F G and Culshaw M 2007 Sinkholes and subsidence: Karst and cavernous rocks in engineering and construction. Berlin, Germany: Springer, 271-345

[11] Johnson K S 2005 Subsidence hazards due to evaporite dissolution in the United States. Environ. Geol. 48(3): 395-409

[12] Johnson K S 2008 Evaporite-karst problems and studies in the USA. Environ. Geol. 53(5): 937-943

[13] Johnson K 2003 Gypsum karst and abandonment of the Upper Mangum Damsite in Southwestern Oklahoma, Evaporite Karst and Engineering/environmental problems in the United States. Oklahoma Geol. Surv. Circ. 109: 85-94

[14] Moradi G, Abbasnejad A R, and Aghajani H F 2009 The investigation of excess seepage of Gheisaragh dam and treatment method. In: Proceedings of 2'nd International Conference on Long Term Behavior of Dams, Graz, Austria, 408-412

[15] Riemer W 2015 Investigation and treatment of problematic foundations for storage dams: Some experience. Engineering Geology for Society and Territory-Volume 6. Springer 773-777

[16] Gutiérrez F, Mozafari M, Carbonel D, Gómez R and Raeisi E 2015 Leakage problems in dams built on evaporites. The case of La Loteta Dam (NE Spain), a reservoir in a large karstic depression generated by interstratal salt dissolution. Eng Geol. 185: 139-154

[17] Aghajani H F 2018 Deciding for remediation of the seepage barrier system in foundation of an Earthfill dam based on the monitoring data and numerical analysis. In: Numerical Analysis of Nonlinear Coupled Problems: Proceedings of the 1 st GeoMEast International Congress and Exhibition, Egypt 2017 on Sustainable Civil Infrastructures, H. Shehata and Y. 
Rashed (Eds). 2018, Springer International Publishing: Cham. 1-12

[18] Lugeon M 1933, Barrage et Géologie. Paris, France

[19] ASTM International 2011 ASTM D5777-00(2011)e1, standard guide for using the seismic refraction method for subsurface investigation. ASTM: West Conshohocken, PA.

[20] Mari J L 1999 Geophysics of Reservoir and Civil Engineering. Paris, France: Editions Technip, 97-215 